\title{
Çocuklarda periton diyalizi uygulaması ve komplikasyonları
}

\author{
Turan YILDIZ1 ${ }^{1}$, Erol KARAASLAN ${ }^{2}$
}

\begin{abstract}
Öz
Günümüzde Böbrek yetmezliği tedavisindeki periton diyalizi kullanımı çocuklarda artmaktadır. Ancak periton diyaliz uygulaması yüksek komplikasyon oranları ile seyretmektedir. En s1k peritonit, kateter tıkanması ve kateter migrasyonu nedeni ile kateter revizyonu gerekmektedir. Bu derlemenin amacı, komplikasyon oranlarını azaltmak için peritoneal kateter yerleştirme prosedürünün ipuçlarını ve uygun kateter tiplerini tanımlamaktır.
\end{abstract}

Yayın Bilgisi

Gönderi Tarihi:19.02.2018

Kabul Tarihi:02.04.2018

Online Yayın Tarihi:31.03.2019

DOI: $10.26453 /$ otjhs.396434

Anahtar Kelimeler: Çocuk, periton diyalizi, kateter; cerrahi, komplikasyon

Sorumlu Yazar

Turan YILDIZ

\section{The peritoneal dialysis procedure and complication in children}

\author{
Turan YILDIZ ${ }^{1}$, Erol KARAASLAN ${ }^{2}$
}

\begin{abstract}
Nowadays, the use of peritoneal dialysis in the treatment of renal failure is increasing in children. However, the use of peritoneal dialysis is associated with high complication rates. Most frequently, revision of catheter is required because of peritonit, occlusion of catheter and migration of catheter. The aim of this study was to describe clues of peritoneal catheter insertion procedure and appropriate types of catheter for decreasing rates of complication.
\end{abstract}

Keywords: Child, peritoneal dialisis, cathater; surgery, complication
Article Info

Received:19.02.2018

Accepted:02.04.2018

Online Published:31.03.2019

DOI: $10.26453 /$ otjhs.396434

Corresponding Author

Turan YILDIZ

\footnotetext{
${ }^{1}$ İnönü Üniversitesi, Turgut Özal Tıp Merkezi Çocuk Cerrahisi AD, Malatya

2 İnönü Üniversitesi, Turgut Özal Tıp Merkezi Anestezi ve Reanimasyon AD, Malatya
}

\section{GíRiș}

Böbrek yetmezliği çocuklarda nadir olup, kronik böbrek yetmezliği çocuklarda milyonda 12,1 oranında görülür ${ }^{1}$. Periton diyalizi (PD), son dönem böbrek yetmezliği olan hastalarda alternatif tedavi yöntemi olarak kullanılmaktadır. Özellikle hemodinamik olarak-stabil olmayan ve yenidoğan bebeklerde tercih edilen tedavi seçeneğidir. ${ }^{1-3}$ Günümüzde son dönem böbrek yetmezliği hastaları arasında kullanım sıklığı artmıştır. $^{4}$

\section{Katater seçimi}

Optimal kateter konusunda kesin bir mutabakat mevcut değildir. Kateterlerin kaf sayısına göre (çift veya tek kaflı), subkutanöz tünel dizaynına göre(kuğu boynu veya Tenkoff) veya intraperitoneal kısımın şekline göre (sarmallı veya düz olması) birçok değişik varyasyonu mevcuttur. ${ }^{5}$ Kuğu boyunlu kateterler çıkış yerinin 
aşağı doğru olması nedeni ile kateter çıkış yeri enfeksiyonu, kateter ucu yer değiştirmesi ve kaf protruzyonu daha az görülür. Sarmallı kateterlerde daha kolay sıvı akışı sağlanmakta, daha az kateter tıkanıklığı, vaskuler yapılarda zarar görme, kateter migrasyonu meydana gelmektedir. Çift kaf 11 kateterlerde ise daha az peritonit, daha az kateter çıkış yeri enfeksiyonu görülmekte ve kateter ömrünün daha uzun olduğu raporlanmıştır. ${ }^{6}$ Ancak yapılan çalışmalarda klasik Tenckhoff katetere diğer kateterlerin üstünlüğünü ispat edilememiş ve kılavuzlarda optimal kateter tavsiyesinde bulunulmamıştır. ${ }^{5}$ Kateterlerin çift katlı olması tercih edilmektedir. Çocuklar için kateterin ucundan sarmallı kısıma kadar $42 \mathrm{~cm}-62,5 \mathrm{~cm}$ boyutunda kateterler kullanılır. İnfantlar için ise kateter başından ucuna kadar $23 \mathrm{~cm}$ lik kateterler kullanılır., ${ }^{2,3}$

\section{Cerrahi prosedür}

İdeal prosedür hala tartışmalıdır. Açık, perkütan veya laparoskopi yardımlı teknik uygulanan prosedürlerdir. ${ }^{2}$ Carpenter ve $\operatorname{ark}^{7}$ laparoskopik işlemi tavsiye etmekte ve komplikasyon oranlarını azalttığını raporlanmaktadır. Ancak Cribbs ve $\operatorname{ark}^{8}$ ise laparoskopinin bir üstünlüğünün olmadığını raporlamıştır. Bu durum bize cerrahın tecrübesine göre uygun tekniği kullanması gerektiğini düşündürtmektedir.

Cerrahi prosedürde amaç kateteri pelvise yerleştirip birinci kafı periton üzerine, ikinci kafı cilt altına yerleştirip kateterin peritoneal ucunun pelvise yerleştirilmesidir. Uzun tünel oluşturulması kateteri sabitler ve ucunun yukarı doğru migrasyonunu engeller. Kateterin diş ucu sol karın duvarından dışarıya çıkartılır. Kateterin ucunun aşağı bakması istenir. Kateter ilerde muhtemel böbrek transplant ihtiyacı nedeni ile sağ alttan çıkartılmaz. Ayrıca gastrostomi ihtiyacı bu çocuklarda söz konusu olabileceğinden gastrostomi bölgesinden de çıkartılması istenmez. 2012 k1lavuzunda sağ üst kadrandan da çıkartılması makul olarak karşılanmıştır. Çıkış yerinin kemer bölgesi ve bez içine de yakın olmaması istenir. Kateterlere çıkış sütürleri önerilmez. ${ }^{2,9}$

Postoperatif PD kateteri aynı gün kullanılabildiği gibi, ideal olanı kateter takılmasını takiben 1-2 hafta beklenip sonra kullanılmasıdır. Erken kullanılan kateterlerden mekanik problemler daha sık raporlanmıştır. ${ }^{2}$ Bazı çalışmalarda ise erken kullanımın sızdırmalara neden olduğu raporlanmış. ${ }^{910}$ Ancak Duzalka ve ark. uygun tedbirler (fibrin yapıştırıcı, küçük volümlü diyaliz ve diyaliz sıvısının bekletilme süresinin kısaltılması) ile komplikasyonda artış tespit edilmediğini raporlamıştır. ${ }^{3}$ PD kateteri erken dönemde kullanılmaya başlanacak ise $10 \mathrm{ml} / \mathrm{kg}$ dozunda başlanması tavsiye edilir. ${ }^{2}$

\section{Komplikasyonlar}

PD uygulaması güvenli bir teknik olarak kabul edilmesine rağmen, cerrahiden sonraki ilk 60 gün boyunca cerrahi komplikasyonlar \%40 gibi yüksek olduğu tahmin edilmektedir. ${ }^{6}$ Özellikle 10 kilonun altındaki çocuklarda daha sık komplikasyon görülür. ${ }^{1,2}$ 
1. Peritonit: Bir y1ldan sonra en s1k kateter revizyonu nedeni peritonit olarak raporlamaktadır. ${ }^{3}$ Peritonit $0-2$ yaş aralığında daha büyük çocuklara oranla daha yüksek görüldüğü belirtilmektedir. Çocuklarda yetişkinlere nazaran daha sı görüldüğ̈ raporlanmıştır. ${ }^{2,11}$ Yetişkinlerle aynı oranda peritonit ile karşılaşıldığını raporlayan yazarlar bulunmaktadır. ${ }^{12}$ Klinik bulgusu bulanık drenaj ve karın ağrısı ile başlar. Olaya ateş, kusma, titreme, abdominal distansiyon ve ilerleyen durumda septik şok eklenir. Kültür sonucuna göre tedavi düzenlenir. Tedavide gram (+) ve gram (-) lere yönelik antibiyotik tedavisi düzenlenir. Kateter, 3-5 günlük tedaviye rağmen cevap alınamayanlarda veya Psödomonas aeruginosa ile fungal peritonit gelişenlerde çekilir. ${ }^{12}$ Lewis ve ark. ise staphylococcus aureus ile peritonit oluşanlarda kateter kaybının daha sık olduğunu raporlamıştır. ${ }^{13}$ Çift kaflı kateter kullanımı, kuğu boyunlu ve bununla ilişkili olarak kateter çıkış yerinin aşağı doğru yönelmesi peritonit oranlarını azalttı̆̆ kabul edilmektedir. Ayrıca preoperatif antibiyotik profilaksisi de peritonit riskini azaltmaktadır. ${ }^{2,9}$

2. Kateterin tıkanması: s1k görülen komplikasyonlardan biridir. ${ }^{1,14}$ En sik omentum tıkanıklık nedeni olur. Kısmi omentektomi yapılanlarda da obstrüksiyon raporlanmıştır. Kateter yerleşiminin tartışmalı olan yönünü, omentektominin rutin olarak uygulanıp uygulanmama kararsızlığıdır. ${ }^{1}$ Pediatrik cerrahi merkezlerinde hastaların \%53-59'unda omentektomi rutin olarak uygulanmaktadır., 8,11 Çocuklarda omentektominin temel nedeni, kateter tıkanıklığının (genellikle omental sarg1 nedeniyle), çocuk yaş grubunda önemli kateter komplikasyonları arasında yer almasıdır. $\mathrm{Cribbs}^{8}$ ve ark. yaptığg çalışmada omentektomi yapılan hastalarda kateterin erken başarısızlık oranının düştüğü belirtilmiştir. Conlin ve ark. 92 çocuk hasta ile yaptığ hastalarda kateter obstrüksiyon oranının \%5 iken, omentektomi yapilmayanlarda bu oran $\% 10$ olarak raporlamıştır. ${ }^{15}$ Stewart ve ark ise omentektomi yapılmasının komplikasyon üzerine herhangi bir etkisinin olmadığını raporlamıştır. ${ }^{14}$ Omentum dışında daha nadiren fimbria, overler, fallopian tüpler, ince barsak ve appandiks epiploica da tıkanıklık nedeni olabilir. Kateterler intraabdominal organlar dışında kan pıhtısı ve fibrin tarafından da tıkanabilir. Ultrason ile kateter tıkanıklığı tespit edilebilir ve tıkanıklık nedeni ayırd edilebilir. Bazı zamanlar ise kateterin değiştirilmesi gerekebilir. ${ }^{1,2,3}$ PD kateter tıkanıklığı cerrahın deneyimi, çocuğun ağırlığ kateter tipi de dahil olmak üzere çoklu parametrelerden etkilendiği kabul edilmektedir. ${ }^{1}$

3. Sivı kaçă̆ı: $\mathrm{s}$ k görülen komplikasyonlardandır. Özellikle düşük doğum ağırlıklı çocuklarda daha sık görülür. 12,4 kilonun altındakilerde 3 kat daha sık görüldüğü raporlanmıştır. ${ }^{14}$ PD kateterinin yerleştirilmesi ile kullanıma başlaması arasındaki sürenin kısa olduğu hastalarda daha sık kaçak olduğu raporlanmaktadır. ${ }^{1,2}$ Uluslararası periton diyalizi 
derneği (ISPD) erken kaçakların önlenmesi için 10.-15. günden sonra önermektedir. Ancak çalışmalarda erken başlanılan ve diyalizin küçük hacimlerle yapıldı̆̆ kaçakların görülmediği raporlanmıştır., ${ }^{3,11}$ Laparoskopi uygulananlarda, uzun tünel oluşturulanlarda, erken dönemde kullanılsa bile sıv1 kaçağı daha az görülür. Fibrin glue çıkış alanında ve submukozal tünelde kullanılması kaçağı engelleyebilmektedir. Bazen bu kaçaklar plevral ve perikardial effüzyon gibi abdomen dışı kaçaklara neden olabilmektedir. Hidrotoraks daha önceden tanı almamış konjenital diafragma hernili hastalarda görülmüsstür. Literatürde extraabdominal sıvı kaçağı 11 çocuk hastada tariflenmiştir. Bazı hastalarda ise sıvı kaçağına bağlı genital ödem gözlemlenmiştir. $\mathrm{Bu}$ hastalarda tedavi olarak diyaliz volumunun azalt1lması (10-20ml/kg) veya hastanın genel durumu ile ilişkili olarak PD'ne ara verilmesi tavsiye edilmektedir. Sonuç alınamayanlarda kateter revizyonu veya PD yerine hemodiyaliz kullanılması değerlendirilmelidir. ${ }^{2,12,16}$

4. Kateter ucunun yer değişikliği: Kateter ucunun drenajın uygun olmadığı alana migrasyonu sonucu oluşur. Genellikle yetersiz extraperitoneal tünel oluşturulan hastalarda karşılaşılır. İki yaşın altında ve 10 kilodan düşük olan hastalarda daha sık görüldüğü raporlanmaktadır., ${ }^{2,7}$ Kateter özellikle $\mathrm{KC}$ ve dalak lojuna yer değiştirir ve diyaliz sıvısının drenajınının sağlanamaması ile sonuçlanır. Direkt grafi ile tüpün yeri belirlenip tanı doğrulanır. Kateter migrasyonu ile karşılaşılan hastla mushil ve lavman uygulanıp barsak peristaltizmi arttırılarak kateter ucunun pelvise yerleşmesi amaçlanır. Eğer kateter pelvise yerleşmez ise floroskopi altında veya laparoskopik olarak kateter posizyonu sağlanmaya çalışılır. ${ }^{1,2}$ Kateter migrasyonunu engellemek için bazı cerrahlar kateteri pelvise tespit etmektedir. Eğer küçük bir insizyonla PD kateteri yerleştirilecekse kateterin floroskopi altında pelvise yerleştirmesi önerilmektedir. Ayrıca laparoskopi, kateterin yerleştirilmesi esnasında uygun görüş alanı sağladığı için tavsiye edilmektedir. ${ }^{17}$

5. Çıkış yeri enfeksiyonu ve tünel enfeksiyonu: Tünel bölgesi veya kateter yerinde şişlik, kızarıklık veya pürülan akıntı olması enfeksiyonun klinik bulgularıdır. $\mathrm{Bu}$ enfeksiyonlar peritonit nedeni olabilmektedir. Tedavide uygun antibiyotik tedavisi, hospitalizasyon ve gerekirse kateter değiştirilmesi gerekir. ${ }^{2,14}$ Preoperatif profilaksi uygulananlarda daha az görüldüğü raporlanmıștır. ${ }^{8}$ Bazı yazarlar kateter çıkış yeri enfeksiyonunu önlemek için günlük Ciprofloxacin solüsyonlarını veya antibiyotikli kremleri kullanmışlardır. Ancak bu tedaviler ile enfeksiyon \%50-60 oranında kontrol altına alınmıştır. Özellikle dirençli enfeksiyonlarda bu tedaviler yetersiz kalmıştır. Dirençli enfeksiyonlarda cuff enfeksiyonun kaynağını oluşturmaktadır. ${ }^{18}$ Dizdar ve ark. ${ }^{18}$ kateter tünel enfeksiyonunda gentamisinin cuff çevresine enjeksiyonunu tavsiye etmektedir. Böylece dirençli enfeksiyonları \%85 oranında 
kontrol altına alınabildiğini ve bu tedavinin çocuklar tarafından iyi tolere edildiğini belirtmektedirler. Eğer tedaviye cevap alınmaz ise kateter revizyonu gerekebilir. ${ }^{3}$

6. Kateter çevresinin granulasyonu: Kateterin çıkış yeri çevresinde granulasyon dokusunun arttığ1 görülür. Gümüş nitrat ile koterizasyon yapılır. Kateterin hareketinin engellenmesi ve travmadan korunması granulasyon dokusunu azaltacaktır. $^{2}$

7. Kanama: PD kateteri takılmasını takiben erken dönemde minör kanamalar ile karşılaşılabilmektedir. Minör adezyonların yırtılması sonu oluşur. Daha ciddi kanamalarda intraabdominal injurilerden şüphelenilmelidir. Kullanılan cerrahi tekniklerdeki gelişmeler, kateterlerdeki gelişmeler nedeni ile daha az kanamalar ile karşılașılmaktadır. ${ }^{2,11}$

Tünelden subkutan yolla olan kanamalar inferior epigastrik damarların yaralanması sonucu meydana gelir. Üzerine bası yapılarak kanama durdurulmaya çalış1lır, eğer kontrol altına alınamazsa cerrahi explorasyon gerekir. Tünel hematomlarında abse oluşumunu engellemek için antibiyotik başlanması gereklidir. ${ }^{2}$

8. Kaf protruzyonu: S1k görülen bir tablo değildir. Sıklıkla kafın cilt altı yağdokusu altına değilde, direkt cildin altına yerleştirilenlerde olur. Bundan dolayı neonatallerde, gelişme geriliği olanlarda ve Prunne Belly sendromlularda daha sik görülür. $\mathrm{Bu}$ durum tünel enfeksiyonu veya çıkış yeri enfeksiyonu olanlarda daha sık görülür. Eğer kaf yerine yerleştirilemez veya yerleştirildiği halde tekrar çıkarsa kateter revizyonu gereklidir. ${ }^{2}$

\section{Abdominal duvar hernileri: Kronik PD} kateterli hastalarda herni s1k görülür. $\mathrm{Bu}$ oran $\% 50$ veya daha yüksek oranlarda görülebilmektedir. Karşılaşılan herniler umblikal, inguinal veya insizyonel herniler olabilir. Yaşı küçük çocuklarda herni daha sık görülür. Bazı cerrahlar laparoskopi esnasında internal ring açık görürlerse inguinal herni gelişimini önlemek için ringi daraltarak herni tamirini tavsiye etmektedir. ${ }^{14,17}$

\section{Enkapsule Peritoneal Sklerosis (EPS):}

Peritoneal membranın diffüz ve belirgin olarak kalınlaşması tablosudur. $\mathrm{Bu}$ tabloda barsak fibrokollagenez bir örtü ile kaplı olup bu durum intestinal obstrüksiyona neden olur ve obstrüksiyon bulguları ile hastalar başvurur. Çocuklarda nadir olmakla birlikte mortalitesi yüksek bir tablodur. Ultrafiltrasyon yetersizdir ve kateter kullanılması durdurulur. Eğer CT yapılırsa peritondaki kalsifikasyonlar görülür. EPS nin histolojik tanısı Tip 4 kollajen, fibroblast, miyofibroblast ve mikrovaskuleritenin artışının görülmesi ile konulur. En önemli risk faktörü uzun süreli PD kateteri tutulan çocuklardır (5 yıldan fazla). Hastalara cerrahi olarak adenolisis ve fibroz membranların eksizyonu gerekebilir. Cerrahiye alternatif olarak yüksek doz kortikosteroid ve immunsupressif ilaçlar (azathiopürin gibi) kullanılabilmektedir. ${ }^{2}$

11. Intestinal perforasyon: Kullanılan kateter ile ilişkili olarak prematüre infanlarda 
raporlanmıştır. İntraabdominal kısımı sarmallı kateterlerde ise bu ihtimal daha düşüktür. ${ }^{12}$

\section{Hastalarda kateter revizyonu}

Radtke ve ark. 10 kilonun altındaki çocukların daha sik revizyona ihtiyaç duyduğunu raporlamıştır. ${ }^{1}$ Kateterin 6 ayın altındaki çocuklarda 1 yıllık sağkalımı \%50 dir, 6-24 aylık çocuklarda ise kateterin 1 yıllık sağkalımı \%83,7 dir. ${ }^{2,11}$ PD kateteri yerleştirmesi sonrası komplikasyon $\% 70$ gibi yüksek oranlarda görülebilmektedir. ${ }^{8}$ Çocuklarda PD kateteri revizyon oranı \%13-34 arasındadır. Revizyona genellikle kateterin ilk takılmasından sonra dört hafta içinde gerekmektedir. ${ }^{3}$ Duzalka ve ark yaptığ çalışmada, PD kateteri revizyonunun en s1k nedeni mekanik disfonksiyon (\%60) olup, s1ras1 ile diğer nedenler peritonit(\%16), tünel enfeksiyonu (\%12) ve sıv1 kaçağı (\%6) olarak raporlanmıştır. ${ }^{3}$ ISPD refrakter peritonit ve fungal peritonitli hastalarda revizyonun iki aşamada yapılması gerektiğini, aynı seansta kateter değişiminin yapılmaması gerektiğini ifade etmektedir. Kateter çıkartıldıktan sonra 4 hafta sonra kateter takılması tavsiye edilmektedir. ${ }^{9}$

\section{SONUÇ}

PD kateteri çocuklarda tercih edilen diyaliz yöntemi olmakla birlikte yüksek komplikasyon oranları ile seyretmektedir. Tecrübeli cerrahi ellerde uygun teknikle yapılan PD kateteri takılma işlemi ile katater ömrünün daha uzun olacağını düşünmekteyiz. $\mathrm{Bu}$ öneriler ile komplikasyon oranlarını düşürmek mümkün olmuş olsa da, küçük çocuklarda komplikasyonlar görülmeye devam etmektedir.

\section{KAYNAKLAR}

1. Radtke J, Schild R, Reismann M, et al. Obstruction of peritoneal dialysis catheter is associated with catheter type and independent of omentectomy: A comparative data analysis from a transplant surgical and a pediatric surgical department. J Pediatr Surg. 2017 Jul 4. pii: S0022-3468(17)30411-6.

2. Fraser N, Hussain FK, Connell R, Shenoy MU. Chronic peritoneal dialysis in children. Int J Nephrol Renovasc Dis. 2015 Oct 7;8:12537.

3. Borzych-Duzalka D, Aki TF, Azocar M, et al. International Pediatric Peritoneal Dialysis Network (IPPN) Registry. Peritoneal Dialysis Access Revision in Children: Causes, Interventions, and Outcomes. Clin J Am Soc Nephrol. 2017 Jan 6;12(1):105-112.

4. Hansson JH, Watnick S. Update on Peritoneal Dialysis: Core Curriculum 2016. Am J Kidney Dis. 2016 Jan;67(1):151-64.

5. Stylianou KG, Daphnis EK. Selecting the optimal peritoneal dialysis catheter. Kidney Int. 2014 Apr;85(4):741-3.

6. Dombros N, Dratwa M, Feriani $M$, et al. EBPG Expert Group on Peritoneal Dialysis. European best practice guidelines for peritoneal dialysis. 3 Peritoneal access. 
Nephrol Dial Transplant. 2005 Dec;20 Suppl 9:ix8-ix12.

7. Carpenter JL, Fallon SC, Swartz SJ, et al. Outcomes after peritoneal dialysis catheter $\begin{array}{llll}\text { placement. J Pediatr } & \text { Surg. } 2016\end{array}$ May;51(5):730-3.

8. Cribbs RK, Greenbaum LA, Heiss KF. Risk factors for early peritoneal dialysis catheter failure in children. J Pediatr Surg. 2010 Mar;45(3):585-9.

9. Warady BA, Bakkaloglu S, Newland J, et al. Consensus guidelines for the prevention and treatment of catheter-related infections and peritonitis in pediatric patients receiving peritoneal dialysis: 2012 update. Perit Dial Int. 2012;32 Suppl 2:S32-S86.

10. Gadallah MF, Mignone J, Torres C, Ramdeen G, Pervez A. The role of peritoneal dialysis catheter configuration in preventing catheter tip migration. Adv Perit Dial. 2000;16:47-50.

11. Zaritsky J, Warady BA. Peritoneal dialysis in infants and young children. Semin Nephrol. 2011 Mar;31(2):213-24.

12. Kara A, Gurgoze MK, Aydin M, et al. Acute peritoneal dialysis in neonatal intensive care unit: An 8-year experience of a referral hospital. Pediatr Neonatol. 2017 Nov 16. pii: S1875-9572(16)30386-2.

13. Lewis MA, Smith T, Postlethwaite RJ, et al. A comparison of double-cuffed with singlecuffed Tenckhoff catheters in the prevention of infection in pediatric patients. Adv Perit Dial 1997;13:274-6.
14. Stewart CL, Acker SN, Pyle LL, et al. Factors associated with peritoneal dialysis catheter complications in children. J Pediatr Surg. 2016 Jan;51(1):159-62.

15. Conlin MJ, Tank ES. Minimizing surgical problems of peritoneal dialysis in children. $\mathrm{J}$ Urol. 1995;154:917-9.

16. Dufek S, Holtta T, Fischbach $M$, et al. European Paediatric Dialysis Working Group. Pleuro-peritoneal or pericardio-peritoneal leak in children on chronic peritoneal dialysis-A survey from the European Paediatric Dialysis Working Group. Pediatr Nephrol. 2015 Nov;30(11):2021-7.

17. Stone ML, LaPar DJ, Barcia JP, et al. Surgical outcomes analysis of pediatric peritoneal dialysis catheter function in a rural region. $\mathbf{J}$ Pediatr Surg. 2013 Jul;48(7):1520-7.

18. Dizdar OS, Ozer O, Erdem S, Gunal AI. Subcutaneous gentamicin injection around the cuff in treatment of resistant exit site infection in peritoneal dialysis patients: a pilot study. Ther Clin Risk Manag. 2017 Jul 20;13:909914. 